\title{
Lumbo Peritoneal Shunt in Management of Cases of Depressed Skull Fractures with Superior Sagittal Sinus Occlusion
}

\author{
AHMED S.K. ABD EL-WAHED, M.D. \\ The Department of Neurosurgery, Faculty of Medicine, Cairo University, Egypt
}

\begin{abstract}
Background: Patients with depressed skull fractures overlying the superior sagittal sinus (SSS) present an ongoing challenge. Many surgeons would opt for a conservative management of these cases if there was no associated deficit to avoid risky sinus surgery. A variable percentage of patients presenting with such fractures suffer from SSS occlusion resulting in Benign Intracranial Hypertension (BIH).
\end{abstract}

Aim of Study: We aim to evaluate SSS patency, evaluate intracranial tension and evaluate options for management in patients with simple depressed skull fractures overlying posterior $2 / 3$ of SSS and not surgically indicated.

Patient and Methods: Prospective study of cases which admitted to Cairo University Hospitals, and Bani sueif University Hospital, Department of Neurosurgery, Accidents and Emergency between Jan. 2014 and December 2015.

Patients with simple and compound depressed skull fractures overlying the SSS and not indicated for surgery, with no other intracranial abnormality, with a Glasgow Coma Scores (GCS) of 12 or better were admitted to the study. Patients underwent Magnetic Resonance Venography (MRV) to determine SSS patency on admission, they were clinically followed up using Computerized Tomography (CT) and repeat MRV when needed. Patients underwent serial lumbar manometry, and were given medical treatment in the form of acetazolamide, furosemide plus low molecular weight heparin and anti platelets. Patients were then assessed and evaluated to be admitted for LP shunt surgery and followed-up.

Results: A total of 12 cases were included in the study, 7 patients had complete SSS occlusion and 5 cases has narrowing with patent SSS. The 5 cases with incomplete SSS occlusion had a stable course with only one case $(20 \%)$ developing elevated intracranial pressure (ICP) not responding to medications and requiring LP shunt. Of the 7 patients with complete occlusion, $100 \%$ developed elevated ICP not responding to medical treatment, and all required LP Shunt insertion, 5 patients developed multiple contusions due to anticoagulant therapy on top of SSS occlusion, with discontinuation of anticoagulants and deterioration of conscious level, 8 patients had LP surgery and showed a stable improving post operative course, 2 patients had restored SSS patency on repeat MRV.

Correspondence to: Dr. Ahmed S.K. Abd El-Wahed, E-Mail: Askamel @gmail.com
Conclusion: Management of depressed skull fractures overlying the SSS remains controversial, patients with partial occlusion have a better prognosis, patients with complete occlusion can improve with best medical treatment. LP shunt is recommended for all cases of SSS occlusion.

Key Words: Superior - Sagittal - Sinus - Occlusion - Pseudo tumor-BIH - Lumbo peritoneal shunt.

\section{Introduction}

PATIENTS with depressed midline skull fractures overlying the superior sagittal sinus (SSS) are controversial to manage and present an ongoing challenge especially in cases involving the middle and posterior $1 / 3$ of the SSS. Many surgeons would opt for conservative management of these cases if there was no associated deficit to avoid potentially risky SSS injury during surgery or need to for repair due to injury by depressed fractured bone $[1,2,3]$.

A variable percentage of patients presenting with such fractures suffer from SSS thrombosis and occlusion resulting in Benign Intracranial Hypertension (BIH). Although recognized for more than a century, in recent years this diagnosis has become more frequently encountered. This is partly due to greater awareness among physicians, neurologists \& neurosurgeons, and partly due to improved noninvasive imaging techniques mainly Magnetic Resonance Venograpgy techniques $[4,5,6]$.

Obstruction of the SSS in some cases produces a clinical syndrome resembling pseudotumor cerebri, and severe vision loss can be the presenting sign of SSS thrombosis $[\mathbf{7 , 8 , 9 ]}$.

It remains an under-recognized condition and because chronic papilledema may cause progressive visual loss, benign intracranial hypertension (BIH) should not be considered as a benign condition and fundal changes and visual function should carefully be monitored $[12,13,14]$. 
We have no reliable data on SSS thrombosis incidence, nor on geographical or racial differences in susceptibility. According to British death certification data from 1952 to 1961, the average mortality from venous sinus thrombosis was $0.4 / 106 /$ year over this period. Assuming a mortality rate of $10-20 \%$ over this period produces an incidence figure of 4-8/106/year [15,16]

Data from a US study in 1993-4 estimated that dural sinus thrombosis might complicate 11.6/100 000 deliveries, although mortality in this survey was zero [13]

Reviewing published literature, there is no solid reporting about incidence of SSS occlusion and thrombosis related to depressed skull fractures and no solid guidelines provided in management of such conditions [14].

\section{Aim of work:}

We aim to evaluate SSS patency, evaluate intracranial tension and evaluate options for management in patients with midline skull fractures overlying the middle and posterior $1 / 3$ of the SSS and not indicated for surgery.

\section{Patients and Methods}

Patients with midline simple and compound depressed skull fractures overlying the middle and posterior 1/3 SSS and not indicated for surgery, with no other associated intracranial abnormality, with a Glasgow Coma Scores (GCS) of 12 or better were admitted to the study. All cases were admitted to Cairo University Hospitals, and Beni Sueif University Hospital, Department of Neurosurgery, Accidents and Emergency between Jan. 2014 and December 2015.

Patients underwent Magnetic Resonance Venography (MRV) to determine SSS patency on admission, they were clinically followed-up using Computerized Tomography (CT) and repeat MRV when needed to check for re-canalization.

\section{Serial funds examination to detected papiledema:}

Patients underwent serial lumbar punctures and manometry procedures to measure cerebero-spinal fluid (CSF) pressure.

Cases found to have elevated CSF pressure were subjected to lumbar aspiration of $50 \mathrm{cc}$ of CSF during the initial lumbar puncture, in addition to that they were given medical treatment in the form of acetazolamide, furosemide plus low molecular weight heparin and anti platelets (aspirin $150 \mathrm{mg}$ and clopidogril) for a period of 14 days. After that the patients were readmitted for follow- up lumbar manometry to determine response to medical treatment.

Patients failing to respond to conservative measures were admitted for Lumbo peritoneal (LP) shunt surgery and followed-up.

\section{Operative procedure:}

All patients were admitted to surgery 10-14 days after confirming persistently high CSF pressure inspire of conservative medical treatment to allow for build up of CSF pressure after confirmatory measurement and to avoid the possibility of infection from the lumbar puncture procedure and also to allow for discontinuation of antiplatelets and low molecular weight heparin $[\mathbf{3 , 4 , 5}]$

Patients were admitted under general inhalational anesthesia lying on one side with the right side up were prepped and draped exposing the lumbar spine and the upper abdomen all the way to the midline.

A midline incision was made corresponding to the Lumbar 3-4 spines and taken down to the level of the lumbar fascia where the spines of the corresponding vertebrae were palpated. A separate incision was made along the right subcostal margin followed by muscle fiber separation of the external oblique, internal oblique, transversus abdominus followed by identification and opening of the fascia transversalis and then identification and opening of the peritoneal cavity [6,7]

A tuohy needle is then introduced between the lumbar spines all the way till theca is punctured and CSF is received. Confirmatory measurement of CSF pressure is done, then the thecal end of the LP shunt is introduced pointing upwards inside $\mathrm{e}$ thecal sac. The tuohy needle is removed and a shunt passer is used to pass the peritoneal end of the shunt to the abdominal subcostal wound where CSF flow is confirmed through the tip before placement inside the peritoneum [7,8]

Wounds are then closed in layers taking special considerations to prevent shunt slippage from either end and also ensuring proper closure of anterior abdominal wall to prevent incisional hernia [9]

\section{Results}

A total of 12 cases were included in the study, 4 were males and 6 were females. Median age was 26, 7 patients had complete SSS occlusion and 5 cases has narrowing with patent SSS.

The 5 cases with incomplete SSS occlusion had a stable course with only one case (20\%) developing elevated intracranial pressure (ICP) not responding 
to conservative measures and requiring LP shunt. Of the 7 patients with complete occlusion, $100 \%$ developed elevated ICP not responding to medical treatment, and all required LP Shunt insertion.

5 patients developed multiple contusions due to anticoagulant therapy on top of SSS occlusion, anticoagulants were discontinued and deterioration of conscious level was observed and followed-up.

8 patients had LP shunt surgery and showed a stable improving post operative course at 3 and 6 months follow-up, 4 patients had restored SSS patency on repeat MRV after 3 months.

2 patients had slippage of peritoneal end and required re surgery to re insert the shunt, one patient had superficial wound infection that was conservatively managed with antibiotics and repeated dressing.

Table (1): Result of evaluation of SSS occlusion by midline depressed skull bone.

\begin{tabular}{lll}
\hline & $\begin{array}{c}\text { Incomplete } \\
\text { occlusion } \\
\text { of SSS }\end{array}$ & $\begin{array}{c}\text { complete } \\
\text { occlusion } \\
\text { of SSS }\end{array}$ \\
\hline Number of patients & 5 & 7 \\
Median age & $24 \mathrm{ys}$ & $28 \mathrm{ys}$ \\
Male: Female & $3: 1$ & $1: 5$ \\
Elevated ICP & $1(20 \%)$ & $7(100 \%)$ \\
Conservative management & $4(80 \%)$ & 0 \\
LP shunt & $1(20 \%)$ & $7(100 \%)$ \\
\hline
\end{tabular}

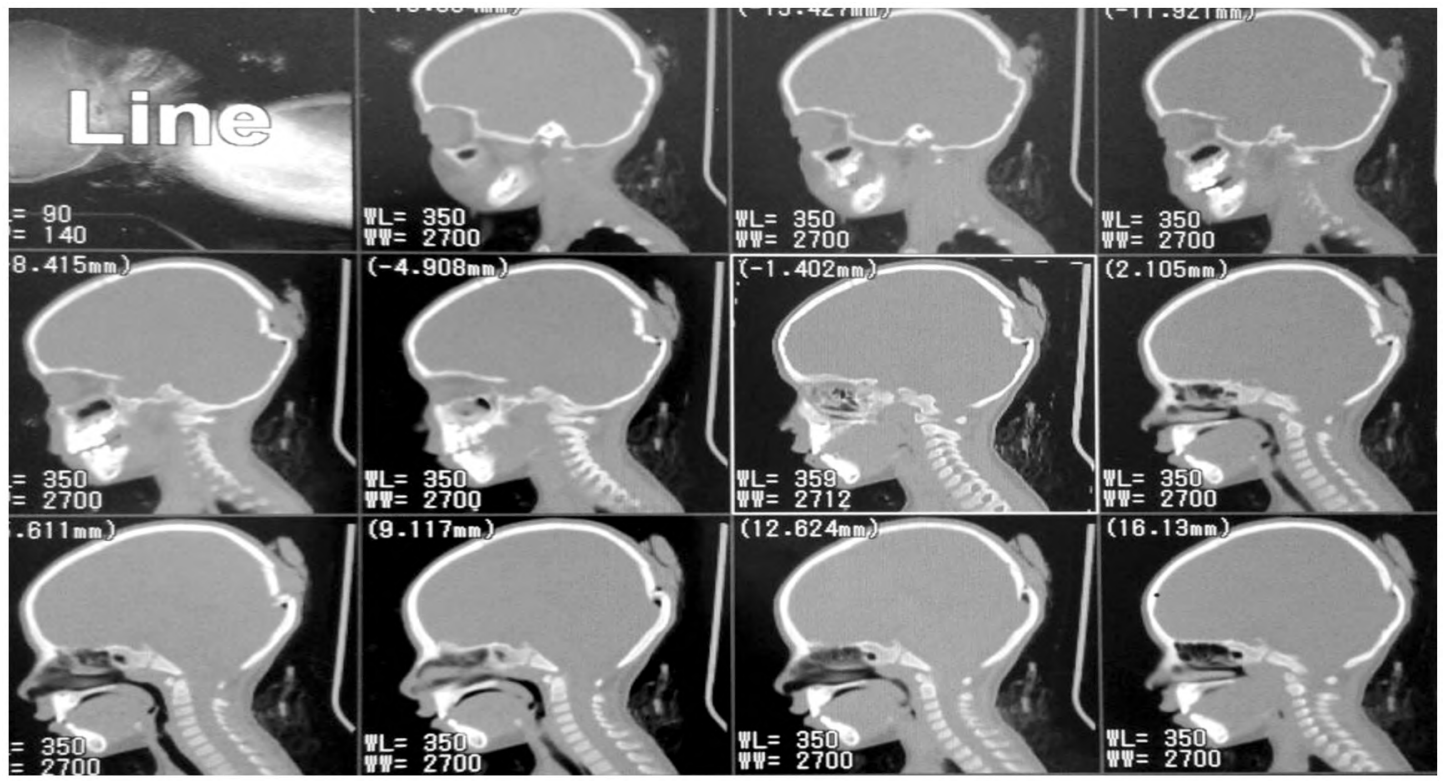

Fig. (1): Sagittal view of CT brain show depressed fracture on SSS.
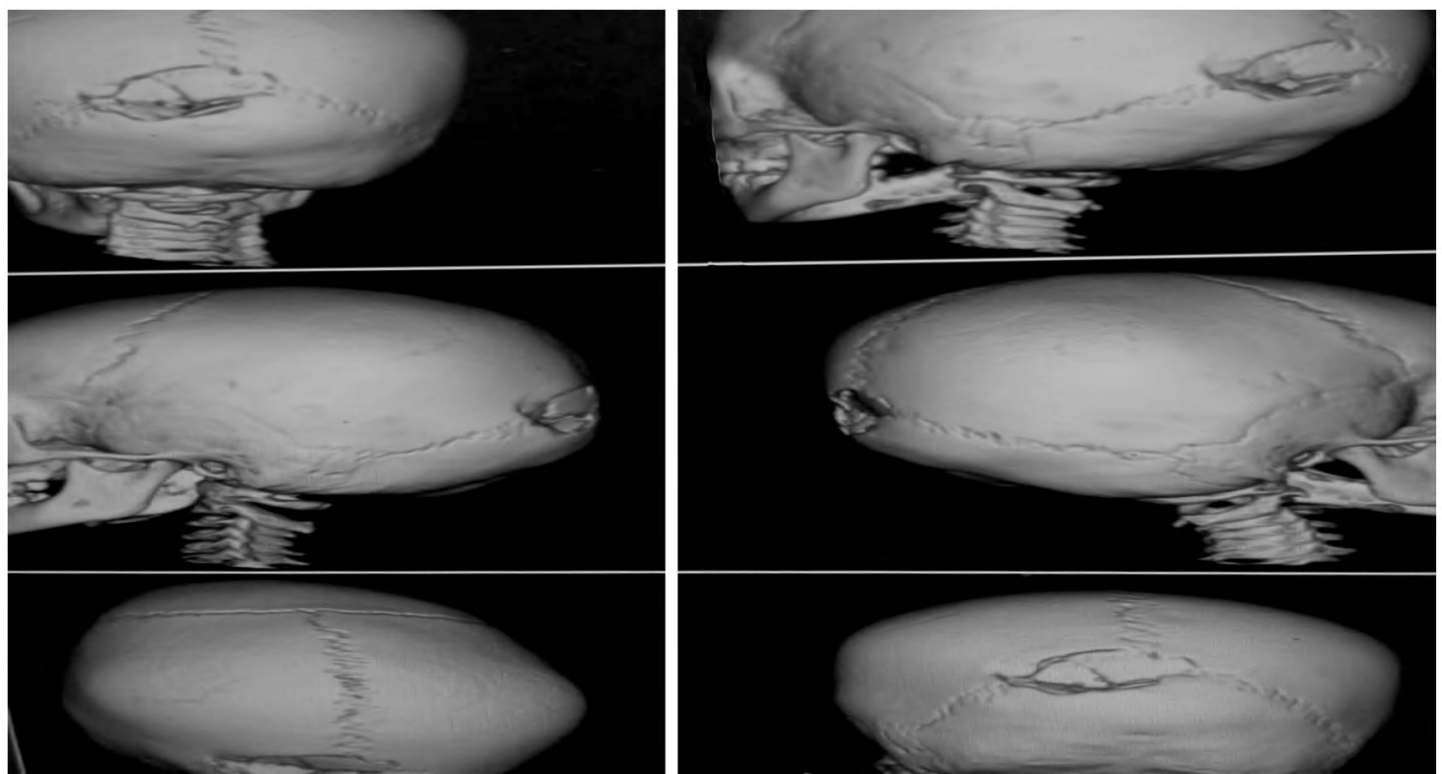

Fig. (2): CT 3D of skull show depressed fracture on SSS. 


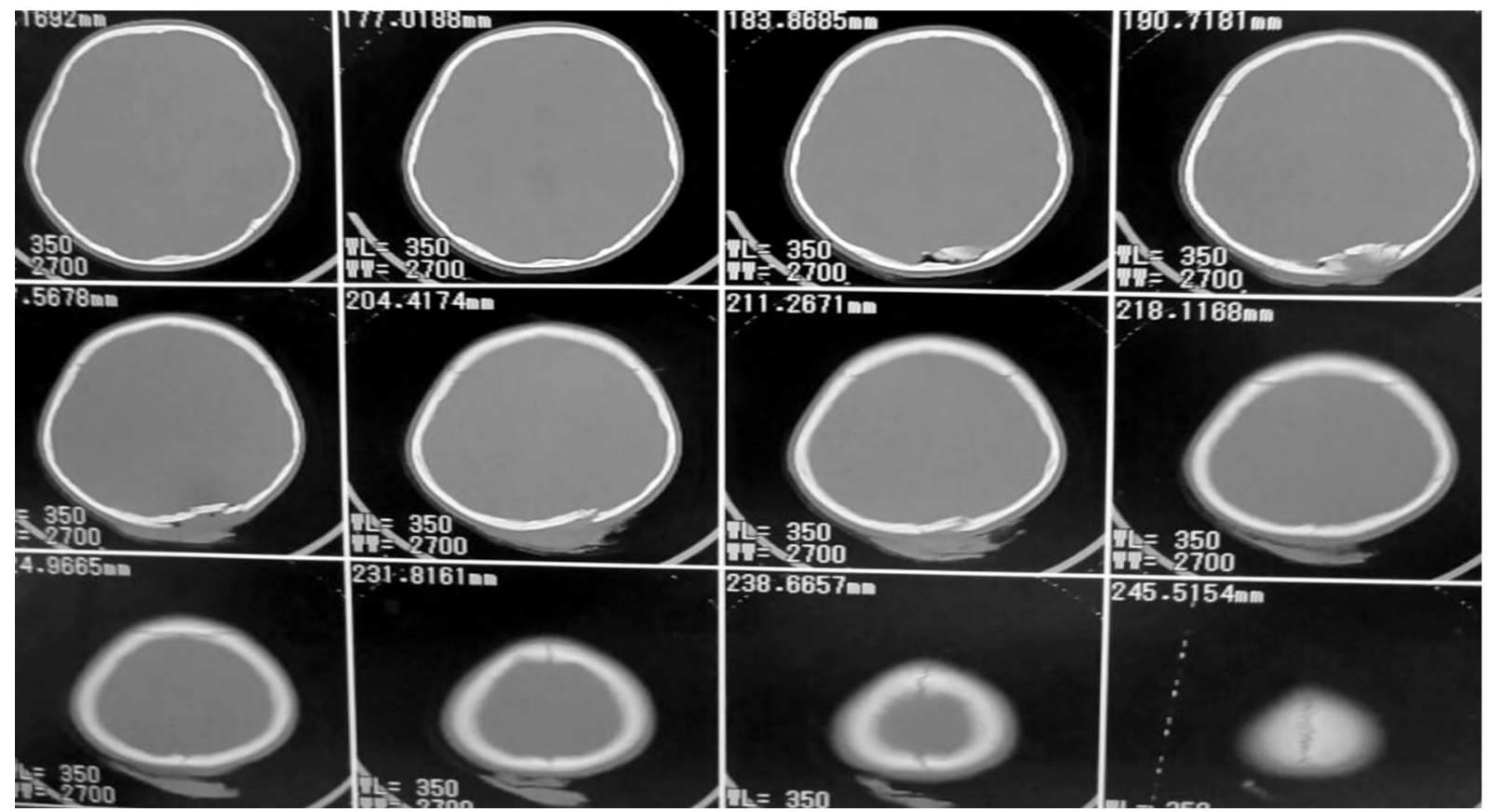

Fig. (3): Axial view of CT brain show depressed fracture on SSS.

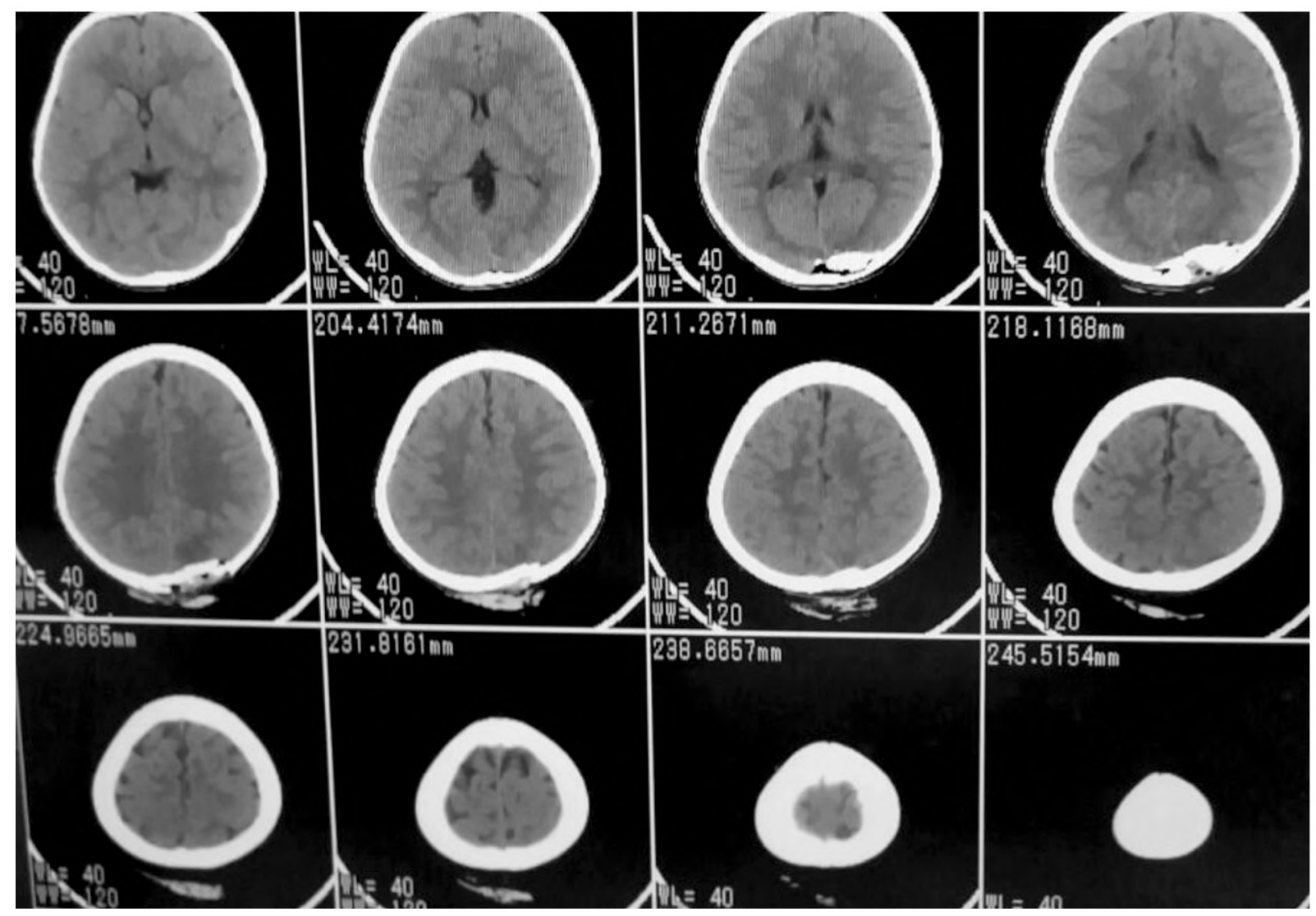

Fig. (4): Axial view of CT brain show depressed fracture on SSS. 


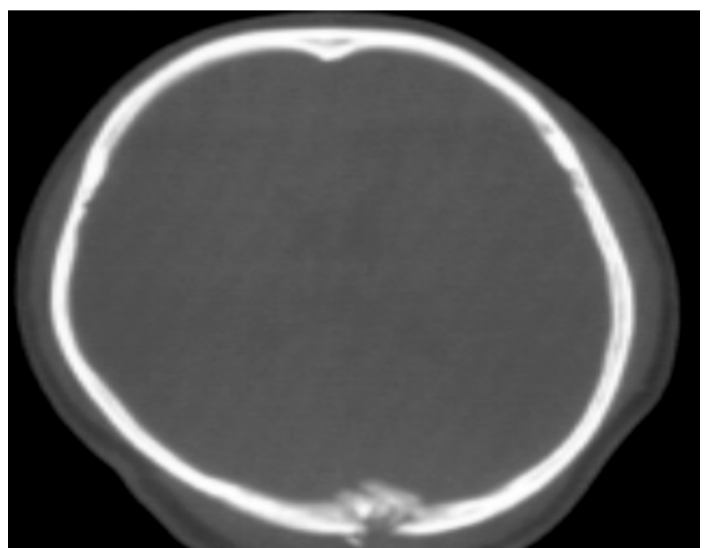

Fig. (5): Axial view of CT brain show depressed fracture on SSS.

\section{Discussion}

Depressed skull fractures overlying major intracranial venous sinuses can result in obstruction of cerebral venous outflow. This in turn can result in localized edema of the brain and subsequent venous infarction. When elevated venous pressure is transmitted to the arachnoid granulations in communication with the SSS, absorption of CSF is impaired [3,4]

CT scan of brain in a patient with progressive intracranial hypertension resulting from CSF malabsorption will fail to demonstrate progressive ventriculomegaly in a brain with normal compliance. Lumbar puncture in this setting is helpful, and often demonstrates markedly increased intrathecal pressures [5,6]. In our study MRV was found to be a good screening tool since it had $100 \%$ sensitivity.

There is a limited number of case reports and case series in the literature describing patients with depressed skull fracture resulting in obstruction of intracranial venous outflow and subsequent intracranial hypertension $[\mathbf{7 , 8}]$.

These manuscripts describe some variation of the following algorithm: If the patient with posttraumatic venous sinus thrombosis caused by a depressed skull fracture remains asymptomatic, conservative management is indicated. If the patient clinically deteriorates because of venous insufficiency or intracranial hypertension relating to communicating hydrocephalus, LP shunts have been advised in cases in which sinus thrombosis develops and failure of conservative management [9].

Ozer et al., reported a series of 17 patients ages ranging from 7 to 48 years, with a mean age of

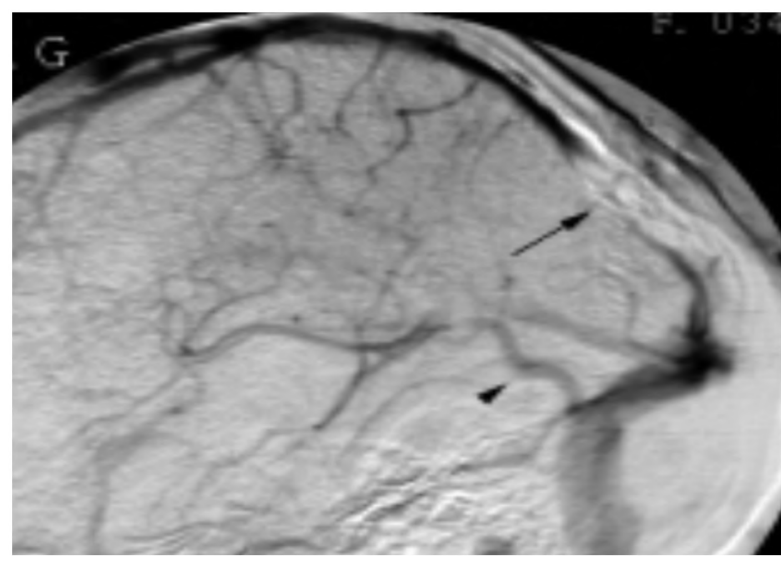

Fig. (6): MRV show Occlusion of SSS.

24.2 years who required surgical elevation of a depressed skull fracture overlying a cranial venous sinus within 24 hours of presentation 11 of the 17 patients were found to suffer profuse bleeding in the operating room, requiring a sum total of 35 Units of blood for transfusion. Two patients in this series deteriorated postoperatively and died [11].

Meier et al., which described 39 patients who suffered a head injury that resulted in traumatic injury of the dural sinuses requiring operative management. The overall mortality rate in this series was $41 \%$, with an intraoperative mortality rate of $20 \%$ [10]

Most practitioners agree that the morbidity involving elevation of a depressed skull fracture overlying a venous sinus is significant, and should be avoided when at all possible $[2,3]$

In contrast to those described above, the surgical risks of LP shunt insertion are much lower, with a documented mortality risk well under $1 \%[4,5]$

We believe that management of a depressed skull fracture resulting in compromise of the underlying venous sinus can be stratified based on symptoms and underlying pathophysiological mechanisms. In asymptomatic patients, conservative management with watchful waiting is indicated. In patients who become symptomatic because of elevated intracranial tension LP shunt is advised.

Because of the significant risks relating to intraoperative hemorrhage associated with elevation of a depressed skull fracture over a venous sinus, other surgical methods for treatment should be contemplated in select patients. If clinical evaluation and neuroimaging studies indicate that symptoms are related to the development of CSF malabsorption, resulting in progressive intracranial 
hypertension, LP shunt placement should be considered as an option for management.

In our work we have encountered a $100 \%$ rate of development of increased ICP in patients suffering from complete SSS occlusion, all of these patients didn't respond to medical treatment and required LP shunt insertion. The grey zone lies within patients with incomplete SSS occlusion out of which only one $20 \%$ required LP shunt.

The major limitation to our study is the number of patients, and we encourage more work involving more cases to document the true rate of incidence of SSS occlusion and accompanying elevation of ICP. In the mean time our main recommendation would be not to overlook the possibility of elevated ICP in cases with midline depressed skull fractures overlying the posterior $2 / 3$ of the SSS even if there are no symptoms present.

\section{Conclusion:}

Management of depressed skull fractures overlying the SSS remains controversial, patients with partial occlusion have a better prognosis, patients with complete occlusion can improve with best medical treatment. LP shunt is recommended for all cases of SSS occlusion.

\section{References}

1- BINDER D.K., SARKISSIAN V., SCHMIDT M.H. and PITTS L.H.: Resolution of intracranial hypertension after elevation of depressed cranial fracture over the superior sagittal sinus: Case report. Neurosurgery, 55: 986, 2004.

2- BISHOP F.S., FINN M.A., SAMUELSON M. and SCHMIDT R.H.: Endovascular balloon angioplasty for treatment of posttraumatic venous sinus thrombosis. Case Report. J. Neurosurg, 111: 17-21, 2009.

3- DE VEBER G., ANDREW M., ADAMS C., BJORNSON B., BOOTH F. and BUCKLEY D.J.: Cerebral sinovenous thrombosis in children. N. Engl. J. Med., 345: 417-423, 2001.

4- DONNOVAN D.J.: Simple depressed skull fracture causing sagittal sinus stenosis and increased intracranial pressure: case report and review of the literature. Surg. Neurol., 63: 380-384, 2005.
5- DRAKE J.M., KULKARNI A.V. and KESTLE J.: Endoscopic third ventriculostomy versus ventriculoperitoneal shunt in pediatric patients: A decision analysis. Childs Nerv. Syst., 25: 467-472, 2009.

6- DU PLESSIS J.J.: Depressed skull fracture involving the superior sagittal sinus as a cause of persistent raised intracranial pressure: A case report. J. Trauma, 34: 290292, 1993.

7- FERRO J.M., CANHOO P., STAM J., BOUSSER M.G. and BARINAGARREMENTERIA F.: Prognosis of cerebral vein and dural sinus thrombosis: Results of the International Study on Cerebral Vein and Dural Sinus Thrombosis (ISCVT). Stroke, 35: 664-670, 2004.

8- MARGULIES S.S. and THIBAULT K.L.: Infant skull and suture properties: Measurements and implications for mechanisms of pediatric brain injury. J. Biomech. Eng., 122: 364-371, 2000.

9- MERIER U., GARTNER F., KNOPF W., KLOTZER R. and WOLF O.: The traumatic dural sinus injury-a clinical study. Acta. Neurochir (Wien), 119: 91-93, 1992.

10- MELTZER H., LOSASSO B., SOBO E.J. and ELTZER H.: Depressed occipital skull fracture with associated sagittal sinus occlusion. J. Trauma, 49: 981, 2000.

11- OZER F.D., YURT A., SUCU H.K. and TEKTAS S.: Depressed fractures over cranial venous sinus. J. Emerg. Med., 29: 137-139, 2005.

12- STAM J.: Thrombosis of the cerebral veins and sinuses. N. Engl. J. Med., 352: 1791-1798, 2005.

13- UZAN M., CIPLAK N. and DASHHTI S.G.: Depressed skull fracture overlying the superior sagittal sinus as a cause of benign intracranial hypertension. Case report. J. Neurosurg., 88: 598-600, 1998.

14-VAN DEN BRINK W.A., PIETERMAN H. and AVEZAAT C.J.: Sagittal sinus occlusion, caused by an overlying depressed cranial fracture, presenting with late signs and symptoms of intracranial hypertension: Case report. Neurosurgery, 38: 1044-1046, 1996.

15- VENDER Jr. and BIERBRAUER K.: Delayed intracranial hypertension and cerebellar tonsillar necrosis associated with a depressed occipital skull fracture compressing the superior sagittal sinus. Case report. J. Neurosurg., 103 (5 Suppl): 458-461, 2005.

16- YOKOTA H., EGUCHI T., NOBAYASHI M. and NIKAIDO Y.: Persistent intracranial hypertension caused by superior sagittal sinus stenosis following depressed skull fracture. Case report and review of the literature. J. Neurosurg., 104: 849-852, 2006. 


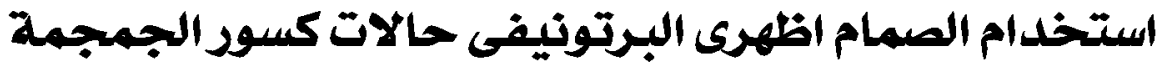

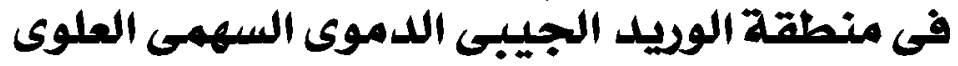

موضوعى : يمثل المرضى الذين يعانون من كسور الجمجمة فى المنطقة التى تعلو على الوريد الجيب السهمى العلوى (SSS) تحدياً مستمراً

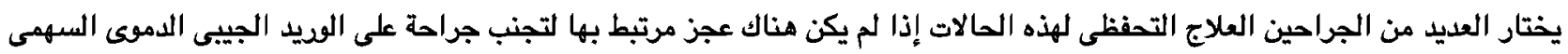

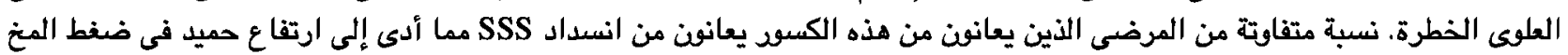

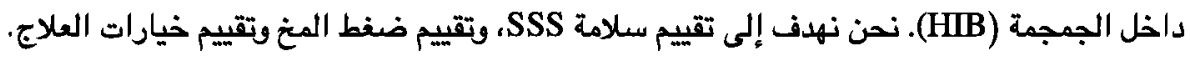

أساليب: المرضى الذين يعانون من كسود الجمجمة البسيطة والمركبة المكسوة التى تغطى SSS ولم يشر إليها لإجراء عملية جراحية،

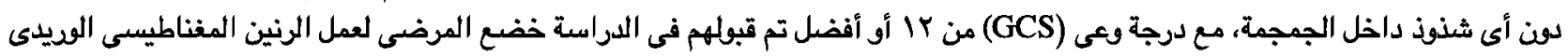

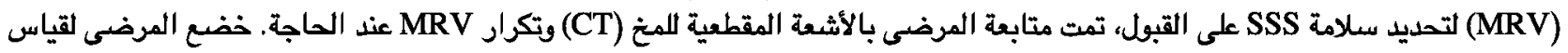

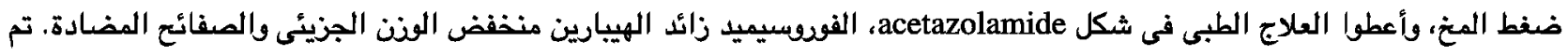

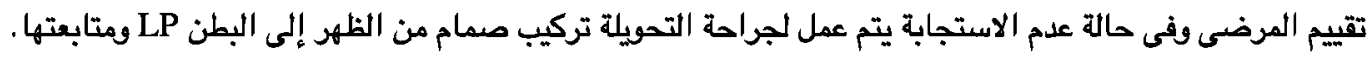

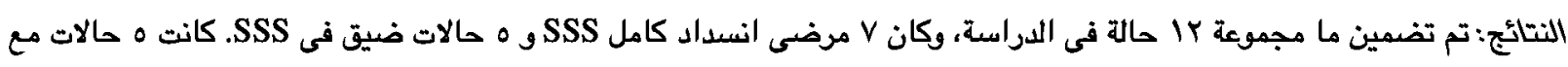

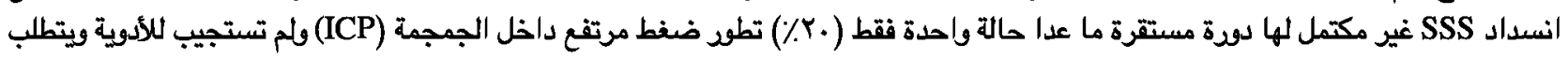

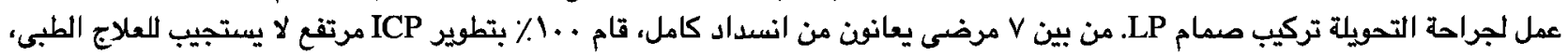

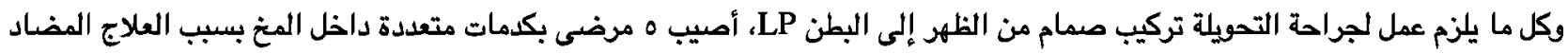

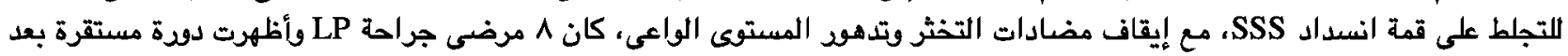

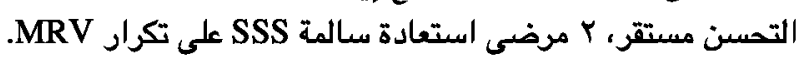

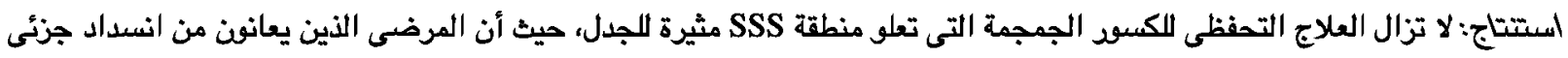

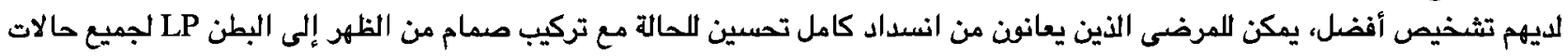

